\title{
Albuminuria, serum creatinine, and estimated glomerular filtration rate as predictors of cardio-renal outcomes in patients with type 2 diabetes mellitus and kidney disease: a systematic literature review
}

\author{
Keith C. Norris ${ }^{1 *}$, Karen E. Smoyer ${ }^{2}$, Catherine Rolland ${ }^{3}$, Jan Van der Vaart ${ }^{4}$ and Eliza Beth Grubb ${ }^{5}$
}

\begin{abstract}
Background: Albuminuria, elevated serum creatinine and low estimated glomerular filtration rate (eGFR) are pivotal indicators of kidney decline. Yet, it is uncertain if these and emerging biomarkers such as uric acid represent independent predictors of kidney disease progression or subsequent outcomes among individuals with type 2 diabetes mellitus (T2DM). This study systematically examined the available literature documenting the role of albuminuria, serum creatinine, eGFR, and uric acid in predicting kidney disease progression and cardio-renal outcomes in persons with T2DM.

Methods: Embase, MEDLINE, and Cochrane Central Trials Register and Database of Systematic Reviews were searched for relevant studies from January 2000 through May 2016. PubMed was searched from 2013 until May 2016 to retrieve studies not yet indexed in the other databases. Observational cohort or non-randomized longitudinal studies relevant to albuminuria, serum creatinine, eGFR, uric acid and their association with kidney disease progression, non-fatal cardiovascular events, and all-cause mortality as outcomes in persons with T2DM, were eligible for inclusion. Two reviewers screened citations to ensure studies met inclusion criteria.

Results: From 2249 citations screened, 81 studies were retained, of which 39 were omitted during the extraction phase (cross-sectional [ $n=16]$; no outcome/measure of interest [ $n=13]$; not T2DM specific $[n=7]$; review article $[n=1]$; editorial $[n=1]$; not in English language $[n=1])$. Of the remaining 42 longitudinal study publications, biomarker measurements were diverse, with seven different measures for eGFR and five different measures for albuminuria documented. Kidney disease progression differed substantially across 31 publications, with GFR loss $(n=9$ [29.0\%]) and doubling of serum creatinine ( $n=5$ [16.1\%]) the most frequently reported outcome measures. Numerous publications presented risk estimates for albuminuria $(n=18)$, serum creatinine/eGFR $(n=13)$, or both combined $(n=6)$, with only one study reporting for uric acid. Most often, these biomarkers were associated with a greater risk of experiencing clinical outcomes. (Continued on next page)
\end{abstract}

\footnotetext{
* Correspondence: kcnorris@mednet.ucla.edu

'David Geffen School of Medicine at UCLA, Division of General Internal

Medicine and Health Services Research, 911 Broxton Avenue, Room 103, Los

Angeles, CA 90024, USA

Full list of author information is available at the end of the article
} 
(Continued from previous page)

Conclusions: Despite the utility of albuminuria, serum creatinine, and eGFR as predictors of kidney disease progression, further efforts to harmonize biomarker measurements are needed given the disparate methodologies observed in this review. Such efforts would help better establish the clinical significance of these and other biomarkers of renal function and cardio-renal outcomes in persons with T2DM.

Keywords: Albuminuria, Serum creatinine, Estimated glomerular filtration rate, Biomarker, Kidney disease progression, Type 2 diabetes mellitus

\section{Background}

Chronic kidney disease (CKD) is a progressive condition characterized by a gradual decline in kidney function, which can result in end-stage renal disease (ESRD) [1]. The global prevalence of CKD is estimated to be between $8 \%$ and $16 \%$ [2], and is thought to exceed $50 \%$ in certain high-risk populations [3]. As of 2013, in the United States alone, more than 30 million adults were projected to have CKD, with the incidence rising profoundly among those aged 65 years and older [4].

The etiology of CKD is multifactorial, with glomerular hypertension and hyperfiltration reflecting the most prominent mechanistic contributors to disease progression [5]. Both systemic hypertension and glomerular hypertension resulting from glomerular hemodynamic changes, are known to provoke injury to the glomeruli. As a consequence, elevated blood pressure can overwhelm normal protection afforded from systemic hypertension to the kidney by autoregulation [5]. Hyperfiltration initiates the renin angiotensin aldosterone system (RAAS), which in turn, increases glomerular permeability and gives rise to albuminuria, proteinuria, and dyslipidemia, while also diminishing glomerular filtration rate (GFR), thus reciprocally leading to hypertension.

Concurrent with hypertension, which occurs in approximately $65 \%$ of the diabetic population [6], hyperglycemia and genetic predisposition are key factors in the development of kidney disease and in its progression [7]. Diabetic kidney disease (DKD) is typically characterized by persistent albuminuria, increasing serum creatinine and a progressive decline in estimated GFR (eGFR). Over time, worsening DKD is associated with increased risk of cardiovascular (CV) and cerebrovascular events, as well as renal morbidity and mortality [7]. Emerging data also suggest uric acid may be a potential marker of CKD [8]. Routine assessment of these key biomarkers is an important dimension of preventive medicine, as it helps to identify those who might benefit from earlier intervention to lower the risk of adverse outcomes.

Although increasing urinary albumin excretion and serum creatinine levels, along with diminished eGFR, are likely important markers of kidney decline, it is unclear whether these biomarkers reflect independent risk factors for kidney disease progression, subsequent outcomes in patients with type 2 diabetes mellitus (T2DM), or both. By extension, numerous pathophysiological mechanisms are implicated in DKD, and in this context, kidney disease progression in patients with T2DM could possibly be delayed or prevented by controlling other measures such as blood glucose or blood pressure levels [9-12, 7, 13]. Indeed, several randomized controlled trials have demonstrated that medications indicated for treatment of T2DM such as glucagon like peptide-1 (GLP-1) [14, 15] and sodium-glucose co-transporter 2 (SGLT-2) inhibitors $[16,17]$ can slow renal disease progression as well as reduce adverse $\mathrm{CV}$ outcomes. Other complementary therapeutic approaches such as utilizing selective endothelin receptor type A (ET-A) antagonists may also help delay renal function decline and subsequently lower the risk of related adverse renal outcomes [18]; albeit the precise beneficial mechanisms conferred from these medications are still undergoing investigation [19].

In light of these findings, a better understanding of the prognostic utility of DKD biomarkers and whether they might be implicated in increasing the risk of adverse renal outcomes in patients with T2DM, would help clarify their clinical value, and guide treatment decisionmaking in everyday clinical practice. The objective of this study was to conduct a systematic literature review (SLR) of the published evidence documenting the role of albuminuria, serum creatinine, eGFR, and uric acid in predicting kidney disease progression and cardio-renal outcomes among patients with T2DM.

\section{Methods}

\section{Databases and search strategy}

Embase, MEDLINE, and Cochrane Central Trials Register and Database of Systematic Reviews and other Cochrane Library assets were searched for human studies published in English between January 2000 and May 2016. Additionally, we performed a PubMed search from 2013 until May 2016, in an effort to capture more recently published studies that may not yet have been indexed in one of the other databases. Implementation and reporting of the present SLR adhered to the guidelines and standards advocated by the National Institute for Health and Care Excellence (NICE) and Preferred Reporting Items for Systematic Reviews and Meta-Analyses (PRISMA) guidelines [20]. 
Although review papers identified in the searches were omitted from this study, the reference lists for each identified review article were hand-screened to include any relevant referenced publications $(n=2)$ that met study inclusion criteria and had not been identified during the database searches.

The data sources above were searched to identify specific observational or non-randomized studies relevant to renal biomarkers and the need for renal replacement therapy. For the current SLR, we adopted the Population, Intervention, Comparator, Outcomes, and Study type (PICOS) criteria to establish our search strategy and inclusion/exclusion criteria. Relevant studies were subsequently identified using text word or MeSH headings, including but not confined to: population terms such as T2DM and non-insulin dependent diabetes; condition/disease outcome terms including renal or kidney replacement or transplantation, renal or kidney failure, chronic renal or kidney disease, end-stage renal or kidney disease; and biomarker/clinical measure terms including GFR, albuminuria, proteinuria, and creatinine.

Only full-text publications were included; congress abstracts were excluded. Studies of behavioral, educational, or clinical practice interventions were included. All review studies (expert, narrative, and systematic reviews, as well as meta-analyses), preclinical studies, pharmacovigilance/ safety studies, case reports, and studies that employed a drug or device intervention were excluded from the SLR.

\section{Screening, critical appraisal, and quality assessment}

At the first-level screening, one reviewer screened the titles of publications identified from the search according to the eligibility criteria. A second reviewer then performed a quality check of $10 \%$ of all screened publications. Where discrepancies existed in a screening decision among the $10 \%$ of publications, the second reviewer examined all of the publications that had been excluded based on the same reason as the study marked with the discrepancy. At the second-level screening, one reviewer screened the abstracts, and if necessary, full texts of publications retained from the first screening stage against the study eligibility criteria. A second reviewer then performed a quality check of $20 \%$ of all screened studies. In the event of a discrepancy, the second reviewer was tasked with checking all studies that had been excluded for the same reason as the study marked with the discrepancy. Any remaining discrepancies regarding study inclusion were resolved by a third reviewer.

Publications of longitudinal studies meeting eligibility criteria that described the role of albuminuria/proteinuria or serum creatinine/uric acid/eGFR in renal disease progression were included in this review. Although uric acid is a less well established potential biomarker of CKD risk, we examined it in this SLR with creatinine/
eGFR. All studies meeting inclusion criteria were assessed for quality using the Downs and Black (D\&B) instrument [21], which is suitable for non-randomized longitudinal clinical and observational studies. The $\mathrm{D} \& \mathrm{~B}$ instrument evaluates (a) the methodological quality (10 items), (b) statistical power (one item), (c) bias (seven items), (d) confounding (six items), and (e) external validity of the study (three items).

\section{Study outcomes}

The primary outcomes examined in this study were renal disease progression, ESRD, non-fatal CV events, and allcause mortality. Renal disease progression reflected any mention of GFR loss, a steep decline in eGFR, at least a $50 \%$ decline in eGFR, a doubling in serum creatinine, or nephropathy progression. Non-fatal CV events comprised non-fatal myocardial infarction or non-fatal stroke.

\section{Statistical considerations}

Key data were extracted from each of the selected publications, where available, and included: study type (e.g. retrospective or prospective); geographic region where the study was conducted; sample size; baseline patient demographics, clinical characteristics and reported medication use; clinical indicators and outcomes of kidney decline and disease progression; follow up duration; and time to renal mortality, CV mortality, all-cause mortality, or receipt of any renal replacement therapy (RRT) including chronic dialysis or transplantation. Descriptive reporting included tabulations of study design and patient characteristics. Risk estimates were extracted from the included publications. These primarily were hazard ratios, and in some cases relative risks (RR), with 95\% confidence limits (where provided) for the association between renal biomarkers and outcomes of interest. Risk estimates reported in the publications were assessed qualitatively by visual inspection for statistical significance as well as directionality (e.g. an increase or reduction in the risk of an outcome of interest according to a particular biomarker). Due to the variation of study biomarker predictors, covariates, outcomes, statistical methods, and risk estimates used in the included publications, quantitative comparison of risk estimates across studies was not possible. Data extracted from the included publications were reported, tabulated, and descriptively assessed in Microsoft Excel 2016 worksheets (Microsoft Corporation, Redmond, WA, USA).

\section{Results}

\section{Literature search and baseline data from included publications}

Database searches identified 2249 potential publications: 787 from Embase, 519 from MEDLINE, 74 from Cochrane Central Trials Register and Database of 


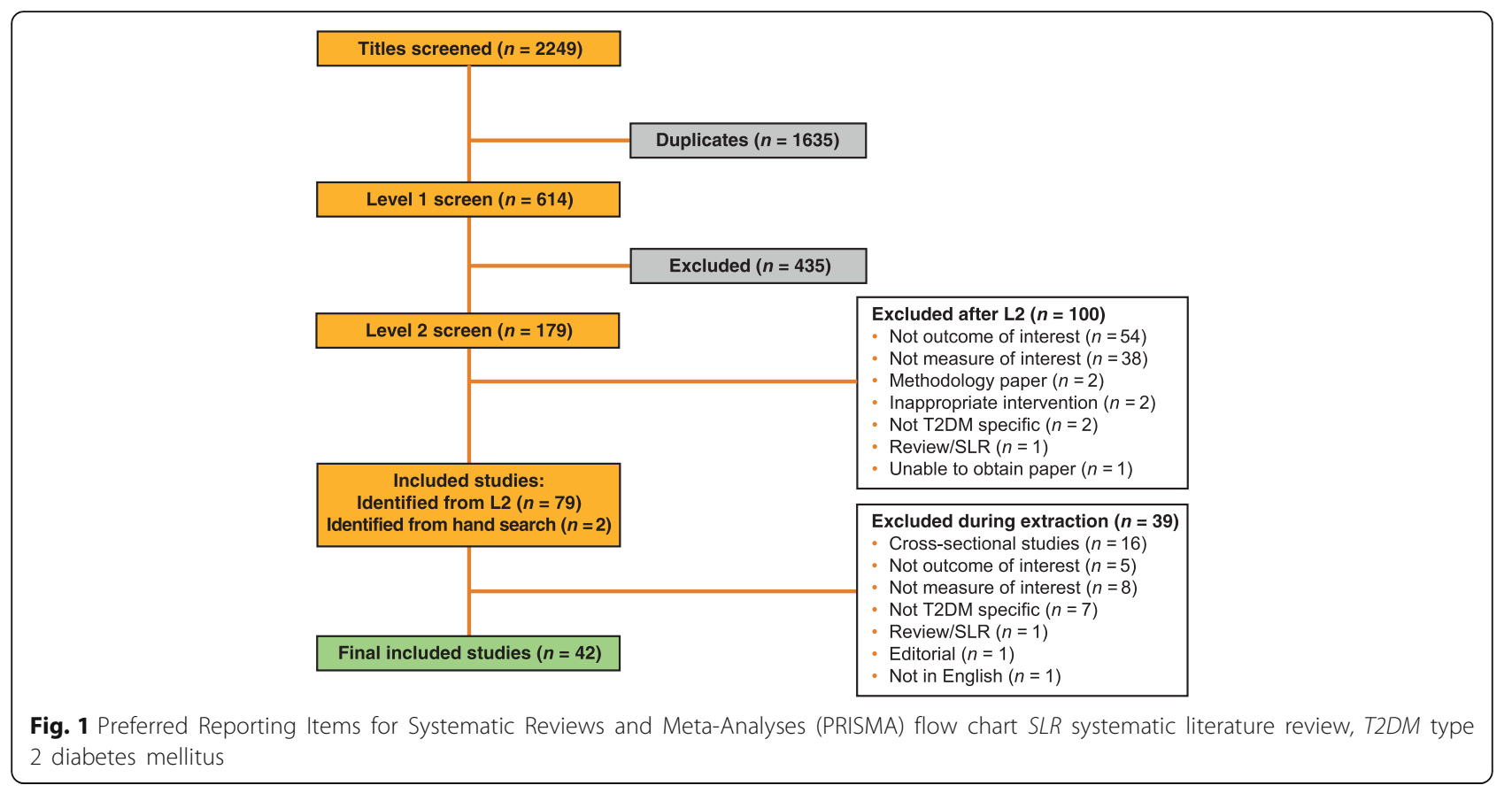

Systematic Reviews, and 868 from PubMed. After initial title screening and following deduplication, 614 publications remained, of which 179 were considered potentially suitable for inclusion. Of these, 42 publications met the relevant criteria to be included in this SLR (Fig. 1 and Table 1). The majority of studies included were prospective $(n=27 ; 64.3 \%)$, and varied in quality (i.e. out of a maximum of 27 points, mean score $=16.52$; range $=12-20$ ) as assessed using the D\&B instrument (Table 1 and Additional file 1: Table 1).

Baseline CKD stage was reported in fewer than 5\% of included publications (Table 2). To estimate patient severity, CKD stage was inferred from eGFR, where available. An extensive range of baseline characteristics was observed, encompassing patients with normal to severely impaired kidney function (Table 2). Seven different measures of eGFR were reported, with the modification of diet in renal disease (MDRD; $n=16$; 43.2\%) [22-31, 11, 32-36] and the Chronic Kidney Disease Epidemiology Collaboration (CKD-EPI; $n=10$; $27.0 \%)[9,25,37,29,38-43]$ the most frequently used (Table 2). Measures of kidney decline/disease progression were diverse. After removing composite end points, 12 different measures were reported across 31 publications (Fig. 2a). GFR loss $(n=9 ; 29.0 \%)$ [23, 44, 10, 37, 30, 45-48] and doubling of serum creatinine $(n=5 ; 16.1 \%)[49,50$, $40,13,51]$ were the most commonly reported measures of kidney disease progression in the included longitudinal studies (Fig. 2a). Measures of albuminuria and proteinuria also varied, with five different measures reported among 33 publications (Fig. 2b). Of these, the most frequently reported markers were urinary albumin-to-creatinine ratio $(n=18$ publications; 54.5\%) [49, 28, 37, 29, 39, 50, 40, 11, $12,41,45,52,46-48,36,51,53]$ and urinary albumin excretion rate $(n=7 ; 21.2 \%)[10,26,50,54,31,42,52]$. A summary of findings from publications providing risk estimates for outcomes of interest by each of the investigated biomarkers is presented in Fig. 3. Biomarkers including baseline albuminuria/proteinuria, serum creatinine/uric acid/eGFR, or both combined, were most often associated with an increased risk of kidney disease progression and all-cause mortality, with more papers reporting a significant rather than a non-significant relationship (Fig. 3).

\section{Biomarkers as independent predictors of clinical outcomes Albuminuria/proteinuria}

Twenty-two publications presented data on albuminuria/proteinuria $[23,44,10,25-28,37,38,30,50,40,31$, $45-47,32,34,48,36,55,51]$, of which 18 provided risk estimates for albuminuria/proteinuria as a biomarker for an outcome of interest (Additional file 1: Table S2). Albuminuria was measured at baseline as well as follow up, both by absolute measure and in terms of doubling from baseline. The included studies documented associations between albuminuria and a wide range of renal outcomes. For instance, albuminuria was identified as a significant risk factor in kidney disease progression, as determined by reduced GFR $(n=5)$ [37, 45-48]; a steep rate of decline in GFR (where albuminuria was elevated, $n=2)[37,30]$; and a doubling of serum creatinine $(n=2)$ [50, 40] (Additional file 1: Table S2). One publication also documented a reduced risk of 
Table 1 Summary of longitudinal publications meeting inclusion criteria and included in the systematic literature review

\begin{tabular}{|c|c|c|c|c|c|c|c|}
\hline Author & Study name & Publication year & $\begin{array}{l}\text { Overall sample } \\
\text { size }(n)\end{array}$ & $\begin{array}{l}\text { Sample size of smallest } \\
\text { sub-group (n) }\end{array}$ & $\begin{array}{l}\text { Mean follow-up } \\
\text { (years) }\end{array}$ & Country & $\begin{array}{l}\text { Overall quality } \\
\text { assessment score (\%) }\end{array}$ \\
\hline $\begin{array}{l}\text { Afghahi } \\
\text { et al. [22] }\end{array}$ & $\begin{array}{l}\text { Swedish National } \\
\text { Diabetes Register }\end{array}$ & 2010 & 3667 & 407 & 5 & Sweden & $18(67 \%)$ \\
\hline $\begin{array}{l}\text { Afkarian } \\
\text { et al. [9] }\end{array}$ & NHANES III & 2013 & 1430 & 658 & 10 & USA & $17(63 \%)$ \\
\hline $\begin{array}{l}\text { Al Suleiman } \\
\text { et al. [77] }\end{array}$ & N/A & 2008 & 35 & N/A & 8 & Saudi Arabia & $16(59 \%)$ \\
\hline $\begin{array}{l}\text { Altemtam } \\
\text { et al. [23] }\end{array}$ & N/A & 2011 & 270 & 94 & 5.2 & UK & $13(48 \%)$ \\
\hline $\begin{array}{l}\text { Alwakeel } \\
\text { et al. [44] }\end{array}$ & N/A & 2011 & 621 & 166 & 10 & Saudi Arabia & $12(44 \%)$ \\
\hline $\begin{array}{l}\text { Andresdottir } \\
\text { et al. [10] }\end{array}$ & N/A & 2014 & 543 & 286 & 5.7 & Denmark & 15 (56\%) \\
\hline $\begin{array}{l}\text { Araki } \\
\text { et al. [49] }\end{array}$ & $\begin{array}{l}\text { Japanese } \\
\text { Elderly Diabetes } \\
\text { Intervention Trial }\end{array}$ & 2012 & 621 & 306 & 4.3 & Japan & 15 (56\%) \\
\hline $\begin{array}{l}\text { Azubike } \\
\text { et al. [56] }\end{array}$ & N/A & 2013 & 22 & N/A & 12 & Nigeria & 15 (56\%) \\
\hline $\begin{array}{l}\text { Bentata } \\
\text { et al. [24] }\end{array}$ & N/A & 2014 & 144 & 26 & 4.1 & Morocco & $13(48 \%)$ \\
\hline $\begin{array}{l}\text { Berhane } \\
\text { et al. [25] }\end{array}$ & $\mathrm{N} / \mathrm{A}$ & 2011 & 2420 & 1503 & 10.2 & USA & 15 (56\%) \\
\hline $\begin{array}{l}\text { Bruno } \\
\text { et al. [26] }\end{array}$ & $\begin{array}{l}\text { Casale } \\
\text { Monferrato } \\
\text { Study }\end{array}$ & 2007 & 1538 & 21 & 11 & Italy & 19 (70\%) \\
\hline Chen et al. [27] & N/A & 2012 & 487 & 65 & 6.6 & Taiwan & $16(59 \%)$ \\
\hline Cox et al. [28] & $\begin{array}{l}\text { Diabetes Heart } \\
\text { Study }\end{array}$ & 2013 & 1220 & N/A & 8.2 & USA & $17(63 \%)$ \\
\hline $\begin{array}{l}\text { De Cosmo } \\
\text { et al. [8] }\end{array}$ & N/A & 2015 & 13,964 & 2540 & 4 & Italy & $20(74 \%)$ \\
\hline $\begin{array}{l}\text { de Hauteclocque } \\
\text { et al. [37] }\end{array}$ & SURDIAGENE & 2014 & 1146 & 486 & 5.7 & France & 19 (70\%) \\
\hline $\begin{array}{l}\text { Dunkler } \\
\text { et al. [29] }\end{array}$ & $\begin{array}{l}\text { ONTARGET } \\
\text { and ORIGIN }\end{array}$ & 2015 & 15,066 & 6766 & 5.5 & Multinational & 15 (56\%) \\
\hline $\begin{array}{l}\text { Elley } \\
\text { et al. [38] }\end{array}$ & $\begin{array}{l}\text { New Zealand } \\
\text { Diabetes Cohort } \\
\text { Study }\end{array}$ & 2013 & 31,613 & 5877 & 7.3 & New Zealand & 16 (59\%) \\
\hline $\begin{array}{l}\text { Jardine } \\
\text { et al. [39] }\end{array}$ & ADVANCE & 2012 & 11,140 & 7377 & 4.8 & Multinational & 19 (70\%) \\
\hline Kitai et al. [30] & N/A & 2015 & 125 & 22 & 75 days & Japan & $20(74 \%)$ \\
\hline $\begin{array}{l}\text { Lambers } \\
\text { Heerspink } \\
\text { et al. [50] }\end{array}$ & RENAAL & 2010 & 701 & N/A & 3.4 & Multinational & 16 (59\%) \\
\hline $\begin{array}{l}\text { Monseu } \\
\text { et al. [40] }\end{array}$ & SURDIAGENE & 2015 & 1371 & 411 & 4.8 & France & $15(56 \%)$ \\
\hline $\begin{array}{l}\text { Moriya } \\
\text { et al. [54] }\end{array}$ & N/A & 2012 & 30 & 9 & 6.2 & Japan & $14(52 \%)$ \\
\hline $\begin{array}{l}\text { Murussi } \\
\text { et al. [31] }\end{array}$ & N/A & 2007 & 173 & 41 & 8 & Brazil & 17 (63\%) \\
\hline $\begin{array}{l}\text { Packham } \\
\text { et al. [11] }\end{array}$ & N/A & 2012 & 3228 & N/A & 2.8 & Multinational & 19 (70\%) \\
\hline $\begin{array}{l}\text { Pavkov } \\
\text { et al. [12] }\end{array}$ & N/A & 2008 & 983 & N/A & 8.4 & USA & $17(63 \%)$ \\
\hline Pavkov et al. [45] & N/A & 2012 & 195 & 88 & 4 & USA & 15 (56\%) \\
\hline $\begin{array}{l}\text { Pavkov } \\
\text { et al. [41] }\end{array}$ & N/A & 2013 & 234 & 76 & 10.7 & USA & 16 (59\%) \\
\hline
\end{tabular}


Table 1 Summary of longitudinal publications meeting inclusion criteria and included in the systematic literature review (Continued)

\begin{tabular}{|c|c|c|c|c|c|c|c|}
\hline Author & Study name & Publication year & $\begin{array}{l}\text { Overall sample } \\
\text { size }(n)\end{array}$ & $\begin{array}{l}\text { Sample size of smallest } \\
\text { sub-group (n) }\end{array}$ & $\begin{array}{l}\text { Mean follow-up } \\
\text { (years) }\end{array}$ & Country & $\begin{array}{l}\text { Overall quality } \\
\text { assessment score (\%) }{ }^{\mathrm{a}, \mathrm{b}}\end{array}$ \\
\hline $\begin{array}{l}\text { Retnakaran } \\
\text { et al. [13] }\end{array}$ & UKPDS & 2006 & 9063 & 4031 & 15 & UK & $17(63 \%)$ \\
\hline $\begin{array}{l}\text { Sinkeler } \\
\text { et al. [42] }\end{array}$ & $\begin{array}{l}\text { RENAAL } \\
\text { and IDNT }\end{array}$ & 2013 & 1872 & 623 & 3 & Multinational & $14(52 \%)$ \\
\hline $\begin{array}{l}\text { Stoycheff } \\
\text { et al. [52] }\end{array}$ & IDNT & 2009 & 1608 & 693 & 2.6 & Multinational & $14(52 \%)$ \\
\hline $\begin{array}{l}\text { Takagi } \\
\text { et al. [46] }\end{array}$ & N/A & 2015 & 1802 & 1655 & 6.9 & Japan & $18(67 \%)$ \\
\hline $\begin{array}{l}\text { Tanaka } \\
\text { et al. [47] }\end{array}$ & N/A & 2015 & 3231 & 137 & 5.9 & Japan & 19 (70\%) \\
\hline $\begin{array}{l}\text { Targher } \\
\text { et al. [32] }\end{array}$ & $\begin{array}{l}\text { Verona } \\
\text { Diabetes } \\
\text { Study }\end{array}$ & 2011 & 2823 & 38 & 5.7 & Italy & 19 (70\%) \\
\hline $\begin{array}{l}\text { Unsal } \\
\text { et al. [33] }\end{array}$ & N/A & 2012 & 122 & 35 & 3.3 & Turkey & $15(56 \%)$ \\
\hline $\begin{array}{l}\text { Viana } \\
\text { et al. [34] }\end{array}$ & N/A & 2012 & 199 & 86 & 6.1 & Brazil & $15(56 \%)$ \\
\hline $\begin{array}{l}\text { Vupputuri } \\
\text { et al. [35] }\end{array}$ & N/A & 2011 & 10,290 & 52 & 3.1 & USA & 17 (63\%) \\
\hline $\begin{array}{l}\text { Wada } \\
\text { et al. [48] }\end{array}$ & N/A & 2013 & 4328 & 534 & 7 & Japan & 19 (70\%) \\
\hline $\begin{array}{l}\text { Yang } \\
\text { et al. [36] }\end{array}$ & $\begin{array}{l}\text { Hong Kong } \\
\text { Diabetes } \\
\text { Registry }\end{array}$ & 2006 & 4438 & 159 & 2.9 & Hong Kong & 19 (70\%) \\
\hline $\begin{array}{l}\text { Yokoyama } \\
\text { et al. [53] }\end{array}$ & JDDM & 2011 & 2954 & 175 & 3.8 & Japan & 16 (59\%) \\
\hline $\begin{array}{l}\text { Yokoyama } \\
\text { et al. [55] }\end{array}$ & N/A & 2012 & 211 & 28 & 4.5 & Japan & $18(67 \%)$ \\
\hline $\begin{array}{l}\text { Yokoyama } \\
\text { et al. [51] }\end{array}$ & N/A & 2013 & 1002 & 303 & 3.8 & Japan & $16(59 \%)$ \\
\hline $\begin{array}{l}\text { Zoppini } \\
\text { et al. [43] }\end{array}$ & $\begin{array}{l}\text { Verona } \\
\text { Diabetes } \\
\text { Study }\end{array}$ & 2012 & 1682 & 263 & 10 & Italy & 19 (70\%) \\
\hline
\end{tabular}

NHANES III Third National Health and Nutrition Examination Survey, SURDIAGENE Survie, Diabete de type 2 et Genetique Study, ONTARGET Ongoing Telmisartan Alone and in Combination with Ramipril Global Endpoint Trial, ORIGIN Outcome Reduction With Initial Glargine Intervention Trial, ADVANCE Action in Diabetes and Vascular Disease: Preterax and Diamicron MR Controlled Evaluation Study, RENAAL Reduction of Endpoints in NIDDM with the Angiotensin II Antagonist Losartan Study, UKPDS UK Prospective Diabetes Study, IDNT Irbesartan Diabetic Nephropathy Trial, JDDM Japan Diabetes Clinical Data Management Study

${ }^{\text {a S}}$ Cored using the Downs and Black quality assessment instrument [21]

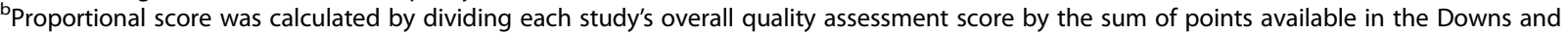
Black instrument

doubling of serum creatinine accompanying macroalbuminuria remission [51]. In four publications, both increased baseline albuminuria as well as elevated levels of albuminuria over time were significantly associated with time to ESRD [25, 37, 45, 36]. However, one of these studies reported no measures of precision (confidence intervals) or test statistics ( $p$-value) [25]; hence, statistical significance could not be ascertained (Additional file 1: Table S2). A separate publication reported a greater risk for ESRD in relation to micro-, macro-, and advanced albuminuria [38]. Four publications reported baseline micro- and macroalbuminuria as significant predictors of experiencing a CV event [40, 34, 48, 55]. For all-cause mortality, seven publications reported a larger risk observed on the background of higher baseline levels of albuminuria $[26,28,40,31,32,34,48]$ (Additional file 1: Table S2).

\section{Serum creatinine/urine creatinine/uric acid/eGFR}

Twenty three publications provided data on baseline serum creatinine, uric acid, and eGFR as risk factors $[23,44,10,49,56,24-28,37,38,50,40,31,45,13,42$, $46,47,32,36,55]$, with 13 reporting the relationship between serum creatinine, uric acid, or eGFR with an outcome of interest (Additional file 1: Table S3). One study found that a higher baseline eGFR was protective against GFR decline [46]. Another reported that an 
Table 2 Baseline characteristics derived from longitudinal study populations

\begin{tabular}{|c|c|c|c|}
\hline Characteristic & Studies reporting characteristic, $N(\%)$ & Category & $n(\%)$ or range \\
\hline Study type & $42(100 \%)$ & $\begin{array}{l}\text { Prospective } \\
\text { Retrospective } \\
\text { Predictive model } \\
\text { Registry }\end{array}$ & $\begin{array}{l}27(64.3 \%) \\
10(23.8 \%) \\
3(7.1 \%) \\
2(4.8 \%)\end{array}$ \\
\hline Age (years) & $42(100 \%)$ & - & 29-100 \\
\hline Race/ethnicity ${ }^{a}$ & $30(71.4 \%)$ & $\begin{array}{l}\text { Caucasian } \\
\text { Black } \\
\text { Asian } \\
\text { Other }\end{array}$ & $\begin{array}{l}13(43.3 \%) \\
10(33.3 \%) \\
11(36.7 \%) \\
11(36.7 \%)\end{array}$ \\
\hline CKD stage determination & $42(100 \%)$ & $\begin{array}{l}\text { CKD stage reported } \\
\text { CKD stage inferred } \\
\text { CKD undetermined }\end{array}$ & $\begin{array}{l}2(4.8 \%) \\
36(85.7 \%) \\
4(9.5 \%)\end{array}$ \\
\hline $\mathrm{BMI}\left(\mathrm{kg} / \mathrm{m}^{2}\right)$ & $40(95.2 \%)$ & - & $16.5-44.9$ \\
\hline Diabetes duration (years) & $35(83.3 \%)$ & - & $1-40$ \\
\hline $\mathrm{HbA1c}(\%)$ & 39 (92.9\%) & - & $5.4-11.9 \%$ \\
\hline Systolic BP (mm Hg) & $41(97.6 \%)$ & - & $100-182$ \\
\hline Diastolic BP (mm Hg) & $37(88.1 \%)$ & - & 53-130 \\
\hline $\operatorname{eGFR}\left(\mathrm{ml} / \mathrm{min} / 1.73 \mathrm{~m}^{2}\right)$ & $38(90.5 \%)$ & - & $10-228$ \\
\hline eGFR assessment method ${ }^{b}$ & $37(88.1 \%)$ & $\begin{array}{l}\text { MDRD } \\
\text { CKD-EPI } \\
\text { JSN } \\
\text { Cockcroft-Gault } \\
51 \text { Cr-EDTA } \\
\text { lohexal clearance } \\
\text { lothalamide clearance }\end{array}$ & $\begin{array}{l}16(43.2 \%) \\
10(27.0 \%) \\
6(16.2 \%) \\
3(8.1 \%) \\
2(5.4 \%) \\
1(2.7 \%) \\
1(2.7 \%)\end{array}$ \\
\hline $\mathrm{ACR}(\mathrm{mg} / \mathrm{gCR})$ & $22(52.4 \%)$ & - & $0.5-8603$ \\
\hline$s \cup A(m g / d L)$ & $3(7.1 \%)$ & - & $4.9-7.4$ \\
\hline
\end{tabular}

$C K D$ chronic kidney disease, $B M I$ body mass index, HbA1c hemoglobin A1C, BP blood pressure, eGFR estimated glomerular filtration rate, MDRD modification of diet in renal disease, CKD-EPI chronic kidney disease epidemiology, JSN Japanese society of nephrology, ACR albuminuria-to-creatinine ratio, sUA serum uric acid

${ }^{a}$ More than one type of race/ethnicity was reported in multiple studies

${ }^{\mathrm{b}}$ More than one assessment method was obtained in two studies

increase in serum uric acid was associated with a greater risk of doubling of serum creatinine [49]. Similarly, a decrement of 1 standard deviation in 24-h urinary creatinine clearance and 24-h urinary creatinine excretion significantly increased the risk of doubling of serum creatinine [50]. Conversely, the risk of doubling of serum creatinine was significantly lower with higher baseline eGFR levels indicative of better kidney function [40], and a higher baseline eGFR was also associated with a lower risk of ESRD [36]. A lower baseline eGFR or steep decline in eGFR over time were both significantly associated with an earlier onset of ESRD [37, 45] (Additional file 1: Table S3). Available data for time to experiencing a $\mathrm{CV}$ event were sparse for these biomarkers, and in some instances, conflicting. For example, non-significant associations between baseline eGFR and time to experiencing a CV event were documented in two publications [27, 55], whereas in another, a significant reduction in the risk of experiencing a CV event was observed [40] (Additional file 1: Table S3). For all-cause mortality, significant predictors included increasing serum creatinine [28] and decreasing eGFR [32].
In addition, higher eGFR concentrations [28, 40,47] and a higher creatinine excretion rate [42] were associated with improved survival (Additional file 1: Table S3).

\section{Albuminuria/proteinuria and serum creatinine/uric acid/eGFR} Six publications reported data for albuminuria/proteinuria and serum creatinine/uric acid/eGFR measured in combination $[25,8,11,35,48,55]$, of which all documented risk estimates for these combined measures with an outcome of interest (Additional file 1: Table S4). Normo-albuminuria in the presence of an eGFR $<30 \mathrm{ml} / \mathrm{min} / 1.73 \mathrm{~m}^{2}$ was associated with kidney disease progression [48], shorter time to ESRD $[25,11]$, and shorter time to experiencing a CV event [48]. One publication documented an increase in risk of kidney disease progression according to higher serum uric acid on the background of normoalbuminuria and an eGFR $<60 \mathrm{ml} / \mathrm{min} / 1.73 \mathrm{~m}^{2}$ [7]. Another publication reported a significant increase in risk of kidney disease progression according to change in eGFR among patients with normo-albuminuria, but 

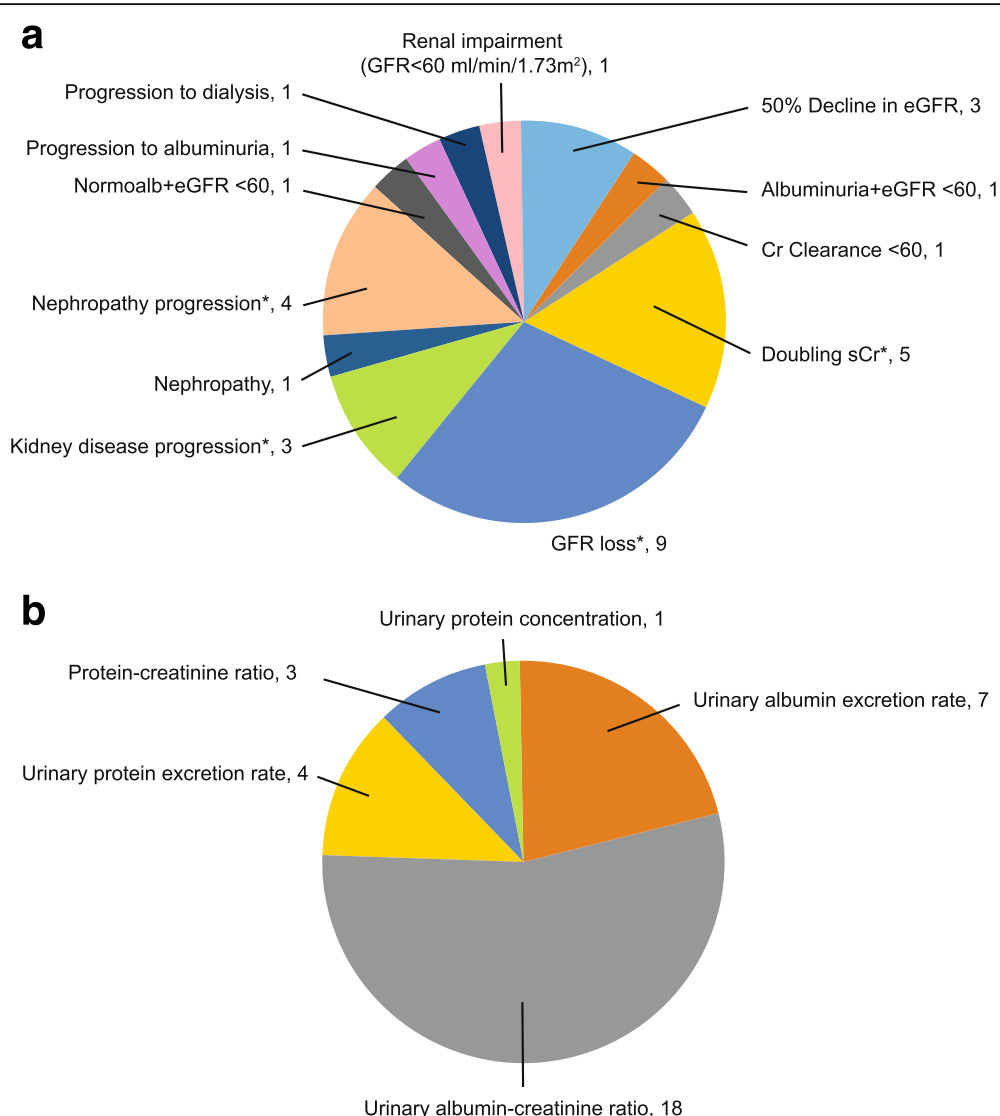

Fig. 2 a Frequency of measures used to define kidney decline/chronic kidney disease progression in 31 longitudinal publications; (b) Frequency of measures used to define albuminuria/proteinuria in 33 longitudinal publications. ${ }^{*} 100 \%$ (3 out of 3) of 50\% decline in eGFR, 60\% (3 out of 5) of doubling of serum creatinine, and 33\% (1 out of 3 ) of kidney disease progression measures included the composite end points of renal replacement therapy initiation, end-stage renal disease, or mortality. Nephropathy progression did not include composite end points, instead, three studies reported "nephropathy progression" and one reported "worsening of nephropathy stage". CKD chronic kidney disease, Cr creatinine, eGFR estimated glomerular filtration rate, GFR glomerular filtration rate, s serum

also reported a significant reduction in risk of kidney disease progression according to changes in eGFR in patients with baseline macro-albuminuria [35]. The latter finding may be explained, in part, by the higher number of patients who might have attained a regression in albuminuria within the macro-albuminuria group. Micro- and macro-albuminuria at baseline were significantly associated with progression of kidney disease [48], a shorter time to ESRD [25, 11] or to a CV event $[48,55]$, regardless of eGFR status (Additional file 1: Table S4). A trend towards increased albuminuria, but not eGFR decline, was significantly associated with shorter time to a $\mathrm{CV}$ event as well as to all-cause mortality [55]. In other studies, time to all-cause mortality was also shorter among patients with baseline micro- [25] and macro$[25,48,55]$ albuminuria. These latter studies did not examine eGFR decline but rather baseline eGFR and similarly found it was not a significant predictor (Additional file 1: Table S4).

\section{Discussion}

This study aimed to systematically review the published literature regarding the role of the biomarkers albuminuria, serum creatinine, eGFR, and uric acid in predicting kidney disease progression and associated cardio-renal outcomes in persons with T2DM. Of the 42 longitudinal publications identified in this review, data reported for the baseline population, biomarkers, and outcomes investigated were for the large part heterogeneous. Biomarker measures tended to be dissimilar between studies, with multiple measures employed to assess eGFR and albuminuria. Further contributing to study heterogeneity, 12 different outcome measures were identified for kidney decline or disease progression alone, which made cross-study comparisons a challenge.

Irrespective of these discrepancies, the data reviewed in this study showed that albuminuria, serum creatinine/ eGFR, or the combination of both, were robust predictors of adverse outcomes in persons with T2DM. Of the three biomarkers, albuminuria was the most frequently 

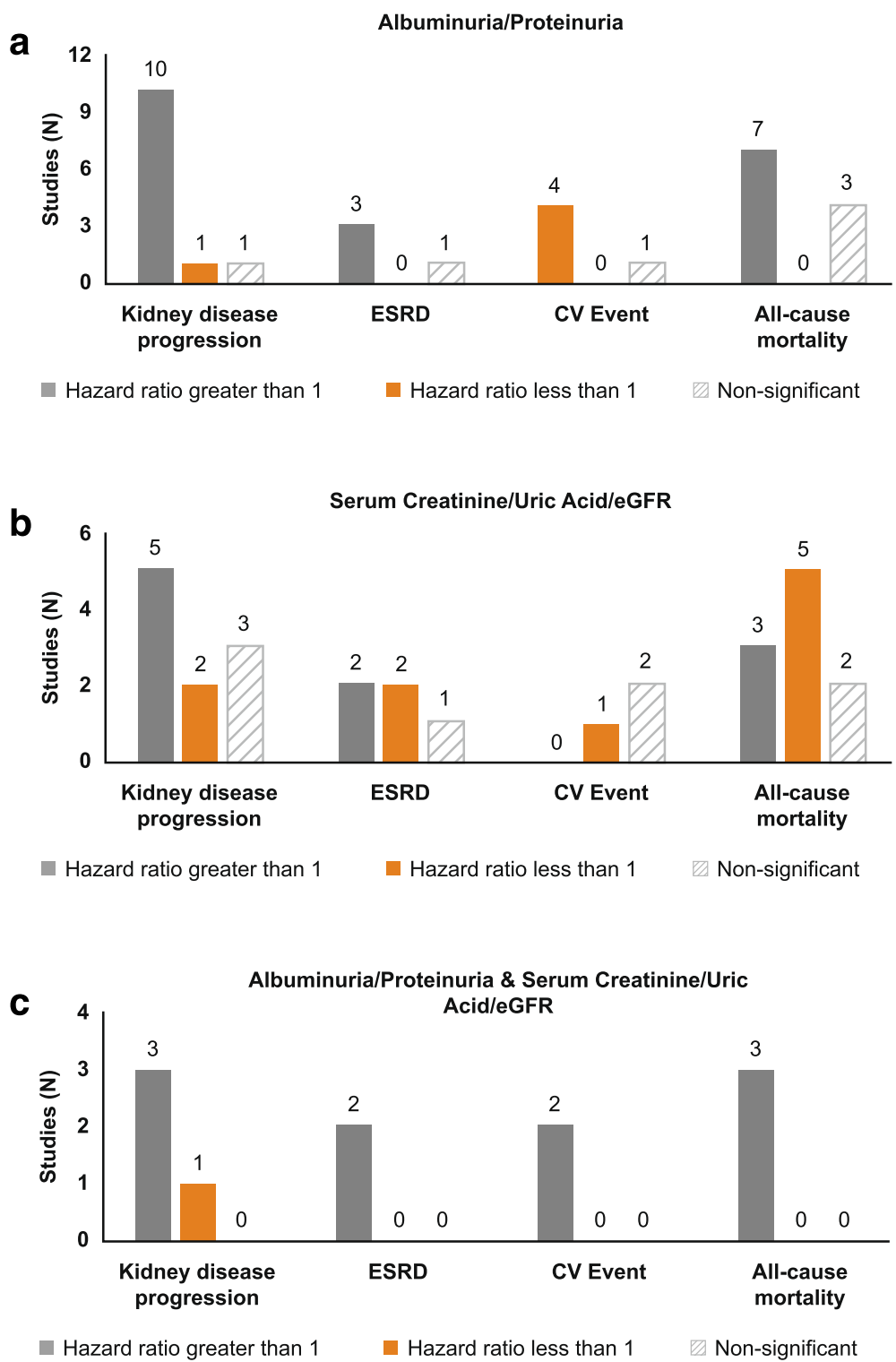

Fig. 3 Number of publications reporting a significant (direct or inverse) or non-significant relationship for risk estimates with clinical outcomes according to the biomarkers albuminuria/proteinuria, serum creatinine/uric acid/eGFR, or both measured simultaneously, in patients with type 2 diabetes mellitus. eGFR estimated glomerular filtration rate, ESRD end-stage renal disease, CV cardiovascular. Panel a. Hazard ratios for studies with albuminuria/proteinuria outcomes. Panel b. Hazard ratios for studies with serum creatinine/uric acid/eGFR outcomes. Panel c. Hazard ratios for studies with albuminuria/proteinuria and serum creatinine/uric acid/eGFR

evaluated, with the majority of studies identified in this review displaying an association with kidney decline and related outcomes, which is fitting with prior investigations $[57,31,58]$. Additional evidence in patients with T2DM has indicated that baseline micro- and macroalbuminuria as well as increasing albuminuria carry higher risks of declining kidney function and associated outcomes, beyond other existing renal biomarkers [59]. In one meta-analysis of five studies encompassing patients with T2DM, patients with micro-albuminuria displayed an almost 4-fold (95\% CI 1.6-8.4) increased RR for developing ESRD as compared with those who had normo-albuminuria [60]. Absolute changes in albuminuria were also considered as precursors to kidney disease progression in individuals with T2DM [61], with ample data further emphasizing the relationship between albuminuria and incipient nephropathy as well as CV outcomes $[62,63]$. Taken together, these findings support the utility of albuminuria as a robust predictor of renal decline. Hence, routine screening for albuminuria in persons with T2DM is considered effective clinical practice for monitoring the onset and progression of kidney disease. 
Nevertheless, in light of the extant epidemiologic evidence, the clinical importance of albuminuria as a prognosticator of kidney disease has recently been challenged $[64,61,65]$. Although albuminuria is commonly used to assess kidney disease development and progression among patients with T2DM, high variability has been observed in this individual marker along with insufficient sensitivity or specificity to detect kidney disease end points on its own $[66,61,67,68]$. By extension, the predictive utility of micro-albuminuria has further come into question due to observed spontaneous remission in people with diabetes $[69,61,70]$. On this basis, seeking out novel biomarkers that can more reliably identify individuals at risk of experiencing poor renal outcomes is warranted. Yet to date, most studies have only assessed the relationship of individual, rather than combined or composite biomarkers, with renal outcomes [71], and no new single biomarker has been shown capable of outperforming albuminuria [72]. Given the numerous pathophysiological processes that encompass DKD (e.g. hyperfiltration, pro-inflammatory, pro-fibrotic, and angiogenic processes) [73], it is doubtful that albuminuria, or any other single biomarker, is individually capable of accurately forecasting the development and progression of renal damage in persons with T2DM [68]. On the other hand, a more comprehensive selection of multiple biomarkers that capture distinct pathways involved in renal impairment would presumably augment risk prediction more effectively than the use of a single biomarker alone. Indeed, extending our efforts in this study beyond the conventional "albuminuric pathway" has been described elsewhere $[66,61,67,71,68]$, and provides impetus for others to establish a panel of biomarkers intended to improve early detection of kidney disease development, as well as its progression in diabetes. For effective clinical use, this panel would need to be highly sensitive and specific, minimally invasive to collect, and cost-effective.

Several publications identified in this review demonstrated that patients with T2DM may present with low eGFR yet be normo-albuminuric. In this context, normo-albuminuric low eGFR has been reported to be more prevalent among older women [67], with these patients often exhibiting a more diverse set of clinical characteristics compared with those who present with low eGFR and higher concentrations of albuminuria $[22,74,75]$. Additionally, renal biomarkers are known to be influenced by clinical features such as age, gender, and genetic disparities, as well as modifiable factors $[61,76]$. To this end, distinct sets of risk factors have been confirmed on the background of low eGFR, and separately for increased albuminuria [13], making it challenging to disentangle whether changes in these biomarkers are complementary of other underlying pathophysiological conditions not linked to kidney disease, or whether they truly reflect important markers of kidney disease development and progression in T2DM. Moving forward, other avenues of research appear warranted that will focus on assessing the predictive value of albuminuria, eGFR and other renal markers for kidney disease end points according to relevant subsets of conventional risk factors (i.e. age, race, or sex-specific disparities) in people with T2DM.

The findings from this SLR illustrated that the risk of kidney function decline and related outcomes tended to vary depending on which biomarker was studied. The available findings demonstrated that the risk as well as the onset of kidney function decline appeared to occur sooner in patients with T2DM who demonstrated an increase in albuminuria, or in the presence of a diminished eGFR over time, and that use of the two biomarkers combined had better predictive ability over time than either alone; although data were sparse. For this reason, studies incorporating these biomarkers in tandem, and their relationship with cardio-renal outcomes, would likely enrich our understanding of the numerous pathways involved in provoking renal impairment, especially given the high individual variability that often accompanies these biomarkers. To further improve prediction based on these studied biomarkers, standardized measures are also needed, as well as more reliable reporting of baseline kidney function and outcomes, particularly for kidney disease progression. Such standardizations will facilitate understanding of the clinical utility of albuminuria and serum creatinine as predictive biomarkers for kidney disease progression as well as related renal and $\mathrm{CV}$ outcomes and mortality risk among patients with T2DM, with the risk perhaps differing among select subgroups.

\section{Limitations}

The observed heterogeneity in the published data clearly limits the generalizability of our findings regarding the importance of albuminuria, serum creatinine, and eGFR as biomarkers for adverse renal outcomes. Although a rigorous, objective, and transparent systematic methodology was implemented and quantitative data were extracted from the included publications, the present SLR was descriptive and qualitative in nature due to the widespread disparity observed among the study designs, baseline population characteristics, biomarkers measured, outcomes reported, and study methods and reporting employed. The majority of included publications did not clearly report baseline CKD stage for the study populations. We therefore referred to eGFR, where available, to estimate baseline kidney function; and it should be noted that these estimates were based on heterogeneous data, as numerous methods were used to 
define eGFR. The evaluated publications, despite meeting inclusion criteria for this SLR, did not report outcomes consistently, particularly for kidney disease progression, which made it difficult to compare predictors across the studies examined. The scientific quality of the data presented varied; for example, some studies had small sample sizes and not all publications reported risk estimates such as hazard ratios or measures of precision. Others failed to report a test statistic for significance. Of the studies that did report hazard ratios, the range of covariates included in survival models also varied, further making it challenging to directly compare risk estimates across each investigation.

\section{Conclusion}

From the literature reviewed, albuminuria, serum creatinine, and eGFR were identified as the major potential predictors for the risk of kidney disease progression in patients with T2DM, with uric acid considered in a subset of articles. These biomarkers displayed some prediction towards kidney disease outcomes, and the few publications that assessed these biomarkers in tandem found additional predictive value for kidney disease progression not apparent for any of the biomarkers alone. Further efforts are needed to improve our understanding of the roles these markers of renal function might play in terms of risk prediction, in light of the measurement and methodologic disparities observed across the extant literature. As the global prevalence of CKD increases, particularly among individuals with T2DM, establishing a more reliable and consistent approach to measuring routine clinical parameters of renal function, along with a more standardized means for defining related outcomes, will help guide clinical decision-making and treatment initiatives designed to mitigate the evergrowing burden of renal disease.

\section{Additional files}

Description of data: The data provided in these additional files are in support of displaying more granular information for describing the individual quality assessment scores based on the Downs and Black quality assessment instrument, as well as the risk estimates according to each of the biomarkers examined in the longitudinal publications.

Additional file 1: Table S1. Individual quality assessment scores for each publication according to the Downs \& Black quality assessment tool. Table S2. Risk estimates for albuminuria/proteinuria measures according to clinical outcomes reported in longitudinal publications. Table S3. Risk estimates for serum creatinine, uric acid, and estimated glomerular filtration rate measures according to clinical outcomes reported in longitudinal publications. Table S4. Risk estimates for combined albuminuria/proteinuria and serum creatinine/uric acid/ estimated glomerular filtration rate measures according to clinical outcomes reported in longitudinal publications. (DOCX $315 \mathrm{~kb}$ )

\section{Abbreviations}

ACR: Albuminuria-to-creatinine ratio; ADVANCE: Action in diabetes and vascular disease: preterax and diamicron MR controlled evaluation study; AER: Albumin excretion rate; BMl: Body mass index; BP: Blood pressure; Cl: Confidence interval; CKD: Chronic kidney disease; CKD-EPI: Chronic kidney disease epidemiology; Cr: Creatinine; CV: Cardiovascular; D \& B: Downs and black; DKD: Diabetic kidney disease; eGFR: Estimated glomerular filtration rate; ESRD: End-stage renal disease; ET-A: Endothelin receptor type A; FMV: First morning void; GFR: Glomerular filtration rate; GLP-1: Glucagon like peptide-1; HbA1c: Hemoglobin A1c; HR: Hazard ratio; IDNT: Irbesartan Diabetic Nephropathy Trial; JDDM: Japan diabetes clinical data management study; JSN: Japanese society of nephrology; MACE: Major adverse coronary event; MDRD: Modification of diet in renal disease; NHANES III: Third National Health and Nutrition Examination Survey; NICE: National Institute for Health and Care Excellence; ONTARGET: Ongoing Telmisartan Alone and in Combination with Ramipril Global Endpoint Trial; ORIGIN: Outcome reduction with initial glargine intervention trial; PAR: Peripheral artery revascularization; PICOS: Population, intervention, comparator, outcomes, and study type; PRISMA: Preferred reporting items for systematic reviews and meta-analyses; RAAS: Renin angiotensin aldosterone system;

RENAAL: Reduction of Endpoints in NIDDM with the Angiotensin II Antagonist Losartan Study; RR: Relative risk; RRT: Renal replacement therapy; S: Serum; SD: Standard deviation; SGLT-2: Sodium-glucose co-transporter 2; SLR: Systematic literature review; sUA: Serum uric acid; SURDIAGENE: Survie, Diabete de type 2 et Genetique Study; T2DM: Type 2 diabetes mellitus; UAC: Urinary albumin concentration; UACR: Urinary albumin-to-creatinine ratio; UAE: Urinary albumin excretion; UCC: Urinary creatinine concentration; UCE: Urinary creatinine excretion; UKPDS: UK prospective diabetes study; UPE: Urinary protein excretion

\section{Acknowledgments}

Editorial assistance was provided by Bríain Ó Hartaigh, PhD, Market Access Solutions, and Brett Wells, PhD, Editorial Solutions, both of Envision Pharma Group. The authors wish to thank Harry Otun, PhD, Envision Pharma Group, for assistance with screening, data extraction, and validation in this study. Funding for these services was provided by AbbVie, Inc.

\section{Funding}

EG and JvdV are employees of AbbVie, Inc. KN has received funding as a consultant from AbbVie, Inc. (none related to this project) and is supported by NIH grants MD000182, UL1TR000124 and P30AG021684. KS and CR are employees of, and hold corporate stock in, Envision Pharma Group. Financial support for the study design, data analyses and interpretation, as well as manuscript development, was provided by AbbVie, Inc.

\section{Availability of data and materials}

All articles retained for this review were acquired via Embase, MEDLINE, Cochrane Central Trials Register and Database of Systematic Reviews, and PubMed, and are available to the public. All data analysed in the present study is included in the published article.

\section{Authors' contributions}

$\mathrm{KS}, \mathrm{CR}$, JVdV, and EG participated in the study design/conduct, and analyses of the data. $K N, K S, C R$, JvdV, and EG provided expertise on data interpretation. KN, KS, CR, JvdV, and EG participated in the initial drafting of the manuscript, and were all involved in revising the manuscript for intellectual content as well as approval of the final version for submission.

\section{Authors' information}

Not applicable.

Ethics approval and consent to participate

Not applicable.

\section{Consent for publication}

Not applicable.

Competing interests

The authors declare that they have no competing interests. 


\section{Publisher's Note}

Springer Nature remains neutral with regard to jurisdictional claims in published maps and institutional affiliations.

\section{Author details}

'David Geffen School of Medicine at UCLA, Division of General Internal Medicine and Health Services Research, 911 Broxton Avenue, Room 103, Los Angeles, CA 90024, USA. Envision Pharma Group, Philadelphia, PA, USA. ${ }^{3}$ Envision Pharma Group, Hammersmith, London, UK. ${ }^{4}$ AbbVie, Hoofddorp, Haarlemmermeer, The Netherlands. ${ }^{5}$ AbbVie, Chicago, IL, USA.

Received: 10 June 2017 Accepted: 21 January 2018 Published online: 09 February 2018

\section{References}

1. KDIGO. 2012 clinical practice guideline for the evaluation and management of chronic kidney disease. Kidney Int Suppl. 2013;3(1):1-150.

2. Jha V, Garcia-Garcia G, Iseki K, Li Z, Naicker S, Plattner B, Saran R, Wang AY, Yang CW. Chronic kidney disease: global dimension and perspectives. Lancet. 2013;382(9888):260-72.

3. Eckardt KU, Coresh J, Devuyst O, Johnson RJ, Kottgen A, Levey AS, Levin A Evolving importance of kidney disease: from subspecialty to global health burden. Lancet. 2013;382(9887):158-69.

4. 2017 USRDS annual data report. Epidemiology of kidney disease in the Uni ted States. National Institutes of Health. Bethesda: National Institute of Diabetes and Digestive and Kidney Diseases; 2017.

5. Matovinovic MS. Pathophysiology and classification of kidney diseases. EJIFCC. 2009:20(1):2-11.

6. Whaley-Connell AT, Sowers JR, McFarlane SI, Norris KC, Chen SC, Li S, Qiu Y Wang C, Stevens LA, Vassalotti JA, et al. Diabetes mellitus in CKD: kidney early evaluation program (KEEP) and National Health and nutrition and examination survey (NHANES) 1999-2004. Am J Kidney Dis. 2008;51(4 Suppl 2):S21-9.

7. Perkovic V, Agarwal R, Fioretto P, Hemmelgarn BR, Levin A, Thomas MC, Wanner C, Kasiske BL, Wheeler DC, Groop PH. Management of patients with diabetes and CKD: conclusions from a "kidney disease: improving global outcomes" (KDIGO) controversies conference. Kidney Int. 2016;90(6):1175-83.

8. De Cosmo S, Viazzi F, Pacilli A, Giorda C, Ceriello A, Gentile S, Russo G, Rossi MC, Nicolucci A, Guida P, et al. Serum uric acid and risk of CKD in type 2 diabetes. Clin J Am Soc Nephrol. 2015;10(11):1921-9.

9. Afkarian M, Sachs MC, Kestenbaum B, Hirsch IB, Tuttle KR, Himmelfarb J, de Boer $\mathrm{H}$. Kidney disease and increased mortality risk in type 2 diabetes. J Am Soc Nephrol. 2013;24(2):302-8.

10. Andresdottir G, Jensen ML, Carstensen B, Parving HH, Rossing K, Hansen TW, Rossing P. Improved survival and renal prognosis of patients with type 2 diabetes and nephropathy with improved control of risk factors. Diabetes Care. 2014;37(6):1660-7.

11. Packham DK, Alves TP, Dwyer JP, Atkins R, de Zeeuw D, Cooper M, Shahinfar S, Lewis JB, Lambers Heerspink HJ. Relative incidence of ESRD versus cardiovascular mortality in proteinuric type 2 diabetes and nephropathy: results from the DIAMETRIC (diabetes mellitus treatment for renal insufficiency consortium) database. Am J Kidney Dis. 2012;59(1):75-83.

12. Pavkov ME, Knowler WC, Hanson RL, Bennett PH, Nelson RG. Predictive power of sequential measures of albuminuria for progression to ESRD or death in pima Indians with type 2 diabetes. Am J Kidney Dis. 2008:51(5):759-66.

13. Retnakaran R, Cull CA, Thorne Kl, Adler Al, Holman RR. Risk factors for renal dysfunction in type 2 diabetes: U.K. prospective diabetes study 74. Diabetes. 2006;55(6):1832-9.

14. Marso SP, Bain SC, Consoli A, Eliaschewitz FG, Jodar E, Leiter LA, Lingvay I, Rosenstock J, Seufert J, Warren ML, et al. Semaglutide and cardiovascular outcomes in patients with type 2 diabetes. N Engl J Med. 2016;375(19):1834-44.

15. Marso SP, Daniels GH, Brown-Frandsen K, Kristensen P, Mann JF, Nauck MA, Nissen SE, Pocock S, Poulter NR, Ravn LS, et al. Liraglutide and cardiovascular outcomes in type 2 diabetes. N Engl J Med. 2016;375(4):311-22.

16. Wanner C, Inzucchi SE, Lachin JM, Fitchett D, von Eynatten M, Mattheus M, Johansen OE, Woerle HJ, Broedl UC, Zinman B. Empagliflozin and progression of kidney disease in type 2 diabetes. N Engl J Med. 2016;375(4):323-34.

17. Zinman B, Lachin JM, Inzucchi SE. Empagliflozin, cardiovascular outcomes, and mortality in type 2 diabetes. N Engl J Med. 2016;374(11):1094.

18. Boels MG, Avramut MC, Koudijs A, Dane MJ, Lee DH, van der Vlag J, Koster AJ, van Zonneveld AJ, van Faassen E, Grone HJ, et al. Atrasentan reduces
Albuminuria by restoring the Glomerular endothelial Glycocalyx barrier in diabetic nephropathy. Diabetes. 2016;65(8):2429-39.

19. Buelli S, Perico L, Benigni A. Untangling the knot in diabetic nephropathy: the unanticipated role of Glycocalyx in the Antiproteinuric effect of Endothelin receptor antagonists. Diabetes. 2016;65(8):2115-7.

20. Shamseer L, Moher D, Clarke M, Ghersi D, Liberati A, Petticrew M, Shekelle P, Stewart LA. Preferred reporting items for systematic review and meta-analysis protocols (PRISMA-P) 2015: elaboration and explanation. BMJ. 2015;349:97647.

21. Downs SH, Black N. The feasibility of creating a checklist for the assessment of the methodological quality both of randomised and non-randomised studies of health care interventions. J Epidemiol Community Health. 1998;52(6):377-84.

22. Afghahi H, Cederholm J, Eliasson B, Zethelius B, Gudbjornsdottir S, Hadimeri $\mathrm{H}$, Svensson MK. Risk factors for the development of albuminuria and renal impairment in type 2 diabetes-the Swedish National Diabetes Register (NDR). Nephrol Dial Transplant. 2011:26(4):1236-43.

23. Altemtam N, Russell J, El Nahas M. A study of the natural history of diabetic kidney disease (DKD). Nephrol Dial Transplant. 2012;27(5):1847-54.

24. Bentata Y, Abouqal R. Does albuminuria predict renal risk and/or cardiovascular risk in obese type 2 diabetic patients? Am J Cardiovasc Dis. 2014;4(1):26-30.

25. Berhane AM, Weil EJ, Knowler WC, Nelson RG, Hanson RL. Albuminuria and estimated glomerular filtration rate as predictors of diabetic end-stage renal disease and death. Clin J Am Soc Nephrol. 2011;6(10):2444-51.

26. Bruno G, Merletti F, Bargero G, Novelli G, Melis D, Soddu A, Perotto M, Pagano G Cavallo-Perin P. Estimated glomerular filtration rate, albuminuria and mortality in type 2 diabetes: the Casale Monferrato study. Diabetologia. 2007;50(5):941-8.

27. Chen $\mathrm{YH}$, Chen HS, Tarng DC. More impact of microalbuminuria on retinopathy than moderately reduced GFR among type 2 diabetic patients. Diabetes Care. 2012;35(4):803-8.

28. Cox AJ, Hsu FC, Carr JJ, Freedman BI, Bowden DW. Glomerular filtration rate and albuminuria predict mortality independently from coronary artery calcified plaque in the diabetes heart study. Cardiovasc Diabetol. 2013;12:68.

29. Dunkler D, Gao P, Lee SF, Heinze G, Clase CM, Tobe S, Teo KK, Gerstein H, Mann JF, Oberbauer R. Risk prediction for early CKD in type 2 diabetes. Clin J Am Soc Nephrol. 2015;10(8):1371-9.

30. Kitai Y, Doi Y, Osaki K, Sugioka S, Koshikawa M, Sugawara A. Nephrotic range proteinuria as a strong risk factor for rapid renal function decline during pre-dialysis phase in type 2 diabetic patients with severely impaired renal function. Clin Exp Nephrol. 2015:19(6):1037-43.

31. Murussi M, Campagnolo N, Beck MO, Gross JL, Silveiro SP. High-normal levels of albuminuria predict the development of micro- and macroalbuminuria and increased mortality in Brazilian type 2 diabetic patients: an 8-year follow-up study. Diabet Med. 2007;24(10):1136-42.

32. Targher G, Zoppini G, Chonchol M, Negri C, Stoico V, Perrone F, Muggeo M, Bonora E. Glomerular filtration rate, albuminuria and risk of cardiovascular and all-cause mortality in type 2 diabetic individuals. Nutr Metab Cardiovasc Dis. 2011;21(4):294-301.

33. Unsal A, Koc Y, Basturk T, Akgun AO, Sakaci T, Ahbap E. Risk factors for progression of renal disease in patient with diabetic nephropathy. Eur Rev Med Pharmacol Sci. 2012;16(7):878-83.

34. Viana LV, Gross JL, Camargo JL, Zelmanovitz T, da Costa Rocha EP, Azevedo MJ. Prediction of cardiovascular events, diabetic nephropathy, and mortality by albumin concentration in a spot urine sample in patients with type 2 diabetes. J Diabetes Complicat. 2012;26(5):407-12.

35. Vupputuri S, Nichols GA, Lau H, Joski P, Thorp ML. Risk of progression of nephropathy in a population-based sample with type 2 diabetes. Diabetes Res Clin Pract. 2011;91(2):246-52.

36. Yang $X L$, So WY, Kong AP, Clarke $P$, Ho CS, Lam CW, Ng MH, Lyu RR, Yin DD, Chow CC, et al. End-stage renal disease risk equations for Hong Kong Chinese patients with type 2 diabetes: Hong Kong diabetes registry. Diabetologia. 2006;49(10):2299-308

37. de Hauteclocque A, Ragot S, Slaoui Y, Gand E, Miot A, Sosner P, Halimi JM, Zaoui $P$, Rigalleau $V$, Roussel $R$, et al. The influence of sex on renal function decline in people with type 2 diabetes. Diabet Med. 2014;31(9):1121-8.

38. Elley CR, Robinson T, Moyes SA, Kenealy T, Collins J, Robinson E, Orr-Walker $B$, Drury PL. Derivation and validation of a renal risk score for people with type 2 diabetes. Diabetes Care. 2013;36(10):3113-20.

39. Jardine MJ, Hata J, Woodward M, Perkovic V, Ninomiya T, Arima H, Zoungas S, Cass A, Patel A, Marre M, et al. Prediction of kidney-related outcomes in patients with type 2 diabetes. Am J Kidney Dis. 2012;60(5):770-8.

40. Monseu M, Gand E, Saulnier PJ, Ragot S, Piguel X, Zaoui P, Rigalleau V, Marechaud R, Roussel R, Hadjadj S, et al. Acute kidney injury predicts major 
adverse outcomes in diabetes: synergic impact with low Glomerular filtration rate and Albuminuria. Diabetes Care. 2015;38(12):2333-40.

41. Pavkov ME, Knowler WC, Hanson RL, Williams DE, Lemley KV, Myers BD, Nelson RG. Comparison of serum cystatin C, serum creatinine, measured GFR, and estimated GFR to assess the risk of kidney failure in American Indians with diabetic nephropathy. Am J Kidney Dis. 2013;62(1):33-41.

42. Sinkeler SJ, Kwakernaak AJ, Bakker SJ, Shahinfar S, Esmatjes E, de Zeeuw D, Navis G, Lambers Heerspink HJ. Creatinine excretion rate and mortality in type 2 diabetes and nephropathy. Diabetes Care. 2013;36(6):1489-94.

43. Zoppini G, Targher G, Chonchol M, Ortalda V, Negri C, Stoico V, Bonora E. Predictors of estimated GFR decline in patients with type 2 diabetes and preserved kidney function. Clin J Am Soc Nephrol. 2012;7(3):401-8.

44. Alwakeel JS, Isnani AC, Alsuwaida A, Alharbi A, Shaffi SA, Almohaya S, Al Ghonaim M. Factors affecting the progression of diabetic nephropathy and its complications: a single-center experience in Saudi Arabia. Ann Saudi Med. 2011;31(3):236-42.

45. Pavkov ME, Knowler WC, Lemley KV, Mason CC, Myers BD, Nelson RG. Early renal function decline in type 2 diabetes. Clin J Am Soc Nephrol. 2012;7(1):78-84.

46. Takagi M, Babazono T, Uchigata Y. Differences in risk factors for the onset of albuminuria and decrease in glomerular filtration rate in people with type 2 diabetes mellitus: implications for the pathogenesis of diabetic kidney disease. Diabet Med. 2015;32(10):1354-60.

47. Tanaka N, Babazono T, Takagi M, Yoshida N, Toya K, Nyumura I, Hanai K, Uchigata Y. Albuminuria and reduced glomerular filtration rate for predicting the renal outcomes in type 2 diabetic patients. Nephrology (Carlton). 2015;20(8):531-8

48. Wada T, Haneda M, Furuichi K, Babazono T, Yokoyama H, Iseki K, Araki S, Ninomiya T, Hara S, Suzuki Y, et al. Clinical impact of albuminuria and glomerular filtration rate on renal and cardiovascular events, and all-cause mortality in Japanese patients with type 2 diabetes. Clin Exp Nephrol. 2014; 18(4):613-20.

49. Araki S, Nishio $Y$, Araki A, Umegaki H, Sakurai T, limuro S, Ohashi Y, Uzu T, Maegawa $H$, Kashiwagi A, et al. Factors associated with progression of diabetic nephropathy in Japanese elderly patients with type 2 diabetes: sub-analysis of the Japanese elderly diabetes intervention trial. Geriatr Gerontol Int. 2012;12(Suppl 1):127-33.

50. Lambers Heerspink HJ, Gansevoort RT, Brenner BM, Cooper ME, Parving HH, Shahinfar S, de Zeeuw D. Comparison of different measures of urinary protein excretion for prediction of renal events. J Am Soc Nephrol. 2010; 21(8):1355-60

51. Yokoyama H, Araki S, Honjo J, Okizaki S, Yamada D, Shudo R, Shimizu H, Sone H, Moriya T, Haneda M. Association between remission of macroalbuminuria and preservation of renal function in patients with type 2 diabetes with overt proteinuria. Diabetes Care. 2013;36(10):3227-33.

52. Stoycheff N, Stevens LA, Schmid CH, Tighiouart H, Lewis J, Atkins RC, Levey AS. Nephrotic syndrome in diabetic kidney disease: an evaluation and update of the definition. Am J Kidney Dis. 2009;54(5):840-9.

53. Yokoyama H, Kanno S, Takahashi S, Yamada D, Honjo J, Saito K, Sone H, Haneda M. Risks for glomerular filtration rate decline in association with progression of albuminuria in type 2 diabetes. Nephrol Dial Transplant. 2011;26(9):2924-30.

54. Moriya T, Tsuchiya A, Okizaki S, Hayashi A, Tanaka K, Shichiri M. Glomerular hyperfiltration and increased glomerular filtration surface are associated with renal function decline in normo- and microalbuminuric type 2 diabetes. Kidney Int. 2012;81(5):486-93.

55. Yokoyama H, Araki S, Haneda M, Matsushima M, Kawai K, Hirao K, Oishi M, Sugimoto $\mathrm{K}$, Sone $\mathrm{H}$, Maegawa $\mathrm{H}$, et al. Chronic kidney disease categories and renal-cardiovascular outcomes in type 2 diabetes without prevalent cardiovascular disease: a prospective cohort study (JDDM25). Diabetologia. 2012;55(7):1911-8

56. Azubike CO, Unuigbe El. Progression of diabetic nephropathy: a twelve-year follow-up of type2 diabetic patients. Journal of medicine and. Biomed Res. 2013;12(1):105-15.

57. Babazono T, Nyumura I, Toya K, Hayashi T, Ohta M, Suzuki K, Kiuchi Y, Iwamoto $Y$. Higher levels of urinary albumin excretion within the normal range predict faster decline in glomerular filtration rate in diabetic patients. Diabetes Care. 2009;32(8):1518-20.

58. Ninomiya T, Perkovic V, de Galan BE, Zoungas S, Pillai A, Jardine M, Patel A, Cass A, Neal B, Poulter N, et al. Albuminuria and kidney function independently predict cardiovascular and renal outcomes in diabetes. J Am Soc Nephrol. 2009;20(8):1813-21.
59. Adler Al, Stevens RJ, Manley SE, Bilous RW, Cull CA, Holman RR. Development and progression of nephropathy in type 2 diabetes: the United Kingdom prospective diabetes study (UKPDS 64). Kidney Int. 2003; 63(1):225-32.

60. Newman DJ, Mattock MB, Dawnay AB, Kerry S, McGuire A, Yaqoob M, Hitman $G A$, Hawke $C$. Systematic review on urine albumin testing for early detection of diabetic complications. Health Technol Assess. 2005;9(30):iii-vi, xiii. 163

61. Macisaac RJ, Ekinci El, Jerums G. Markers of and risk factors for the development and progression of diabetic kidney disease. Am J Kidney Dis. 2014;63(2 Suppl 2):S39-62.

62. Gerstein HC, Mann JF, Yi Q, Zinman B, Dinneen SF, Hoogwerf B, Halle JP, Young J, Rashkow A, Joyce C, et al. Albuminuria and risk of cardiovascular events, death, and heart failure in diabetic and nondiabetic individuals. JAMA. 2001;286(4):421-6.

63. Klausen K, Borch-Johnsen K, Feldt-Rasmussen B, Jensen G, Clausen P, Scharling H, Appleyard M, Jensen JS. Very low levels of microalbuminuria are associated with increased risk of coronary heart disease and death independently of renal function, hypertension, and diabetes. Circulation. 2004;110(1):32-5.

64. Caramori ML, Fioretto P, Mauer M. The need for early predictors of diabetic nephropathy risk: is albumin excretion rate sufficient? Diabetes. 2000;49(9): 1399-408.

65. Stanton RC. Frontiers in diabetic kidney disease: introduction. Am J Kidney Dis. 2014;63(2 Suppl 2):S1-2.

66. Hojs R, Ekart R, Bevc S, Hojs N. Biomarkers of renal disease and progression in patients with diabetes. J Clin Med. 2015;4(5):1010-24.

67. RJ MI, Ekinci El, Jerums G. Progressive diabetic nephropathy. How useful is microalbuminuria?: contra. Kidney Int. 2014;86(1):50-7.

68. Schutte E, Gansevoort RT, Benner J, Lutgers HL, Lambers Heerspink HJ. Will the future lie in multitude? A critical appraisal of biomarker panel studies on prediction of diabetic kidney disease progression. Nephrol Dial Transplant. 2015;30(Suppl 4):iv96-104.

69. Levey AS, Coresh J. Chronic kidney disease. Lancet. 2012;379(9811):165-80.

70. Perkins BA, Ficociello LH, Silva KH, Finkelstein DM, Warram JH, Krolewski AS. Regression of microalbuminuria in type 1 diabetes. N Engl J Med. 2003; 348(23):2285-93

71. Pena MJ, Heinzel A, Heinze G, Alkhalaf A, Bakker SJ, Nguyen TQ, Goldschmeding R, Bilo HJ, Perco P, Mayer B, et al. A panel of novel biomarkers representing different disease pathways improves prediction of renal function decline in type 2 diabetes. PLoS One. 2015;10(5):e0120995.

72. Parving HH, Persson F, Rossing P. Microalbuminuria: a parameter that has changed diabetes care. Diabetes Res Clin Pract. 2015;107(1):1-8.

73. Fechete R, Heinzel A, Perco P, Monks K, Sollner J, Stelzer G, Eder S, Lancet D, Oberbauer R, Mayer $\mathrm{G}$, et al. Mapping of molecular pathways, biomarkers and drug targets for diabetic nephropathy. Proteomics Clin Appl. 2011;5(56):354-66.

74. Penno G, Solini A, Bonora E, Fondelli C, Orsi E, Zerbini G, Trevisan R, Vedovato M, Gruden G, Cavalot F, et al. Clinical significance of nonalbuminuric renal impairment in type 2 diabetes. J Hypertens. 2011; 29(9):1802-9.

75. Yokoyama H, Sone H, Oishi M, Kawai K, Fukumoto Y, Kobayashi M. Prevalence of albuminuria and renal insufficiency and associated clinical factors in type 2 diabetes: the Japan diabetes clinical data management study (JDDM15). Nephrol Dial Transplant. 2009;24(4):1212-9.

76. Harjutsalo V, Groop PH. Epidemiology and risk factors for diabetic kidney disease. Adv Chronic Kidney Dis. 2014;21(3):260-6.

77. Al Suleiman MH, Kfoury HK, Jondeby MS, Burgos NS, Al Hayyan H, Al Sayyari A. Progression of diabetic nephropathy in Saudi patients with type 2 diabetes mellitus. Endocrinologist. 2008;18(5):230-2. 